\title{
Does silodosin offer better results than tamsulosin as medical expulsive treatment after shock wave lithotripsy for single distal ureteric stones?
}

\author{
Catalin Pricop ${ }^{1}$, Dragomir Nicolae Șerban², Ionela Lacramioara Șerban², Alin Adrian Cumpanas³ ${ }^{3}$ Dragoș Puia ${ }^{1}$ \\ 1Department of Urology, “Gr. T. Popa” University of Medicine and Pharmacy, “C. I. Parhon” Hospital, lasi, Romania \\ ${ }^{2}$ Department of Physiology, "Gr. T. Popa” University of Medicine and Pharmacy, lasi, Romania \\ ${ }^{3}$ Department of Urology, Victor Babeș University of Medicine and Pharmacy, Timisoara, Romania
}

Videosurgery Miniinv 2020; 15 (4): 602-607

DOI: https://doi.org/10.5114/wiitm.2020.92307

\begin{abstract}
Introduction: Different antagonists of aadrenergic receptors ( $\alpha$-blockers) have been used as medical expulsive treatment (MET) after extracorporeal shock wave lithotripsy (ESWL).

Aim: To retrospectively evaluate the expulsion rate of fragments after extracorporeal shock wave lithotripsy performed for single ureteral stones followed by different medical expulsive treatments.

Material and methods: We retrospectively analyzed stone expulsion rates of 190 patients treated by shock wave lithotripsy (SWL) for single, 5 to $10 \mathrm{~mm}$, symptomatic and uncomplicated distal ureteric stones, treated with tamsulosin $0.4 \mathrm{mg}$, silodosin $8 \mathrm{mg}$ or silodosin $4 \mathrm{mg}$ as MET. Beside the stone-free rate after 4 weeks of treatment, we also investigated the pain intensity using the visual analogue scale (VAS), adverse events induced by the medication, safety of drug administration and the reasons for possible early treatment discontinuation.

Results: Silodosin $8 \mathrm{mg}$ and tamsulosin $0.4 \mathrm{mg}$ have similar results in terms of stone-free rate. For silodosin $4 \mathrm{mg}$ the stone-free rate was significantly lower than for the previous two drugs. In patients treated with silodosin $4 \mathrm{mg}$ the VAS was significantly higher than in patients treated with silodosin $8 \mathrm{mg}$ or tamsulosin $0.4 \mathrm{mg}$, for all the follow-up visits.

Conclusions: Alpha-blocker treatment after ESWL with silodosin $8 \mathrm{mg}$ offers a similar stone-free rate compared with tamsulosin $0.4 \mathrm{mg}$, being well tolerated. A lower dose of silodosin (4 mg) has significantly poor results, irrespective of ureteric stone size, with more frequent renal colic and severe pain.
\end{abstract}

Key words: extracorporeal shock wave lithotripsy, expulsion rate, $\alpha$-blockers.

\section{Introduction}

The stone-free rates after extracorporeal shock wave lithotripsy (ESWL) of renal/ureteric fragments are widely discussed in the literature [1-6]. Spontaneous elimination of distal ureteric stones should occur as fast as possible, with minimal pain and without expensive urological procedures such as ESWL or retrograde ureteroscopy (URS). To facilitate spontaneous elimination of stone fragments, various classes of drugs are used (either single or combined drugs): non-steroidal anti-inflammatory drugs (NSAID), inhibitors of calcium channels (calcium channel blockers), inhibitors of $\alpha$-adrenergic receptors ( $\alpha$-blockers), corticosteroids, diuretics and hormones. Spontaneous elimination without medical expulsive treatment (MET) was reported in 25-50\% 
of the patients for distal ureteric stones of 5 to $10 \mathrm{~mm}$ diameter (or even higher if the follow-up period is prolonged) but we need to consider the possible complications that may occur, from bothersome symptoms to urinary infection or renal dysfunction [7]. In fact, "watchful waiting" is not an option for such patients, various MET schemes, SWL, URS, or diverse combinations being recommended [8-10].

Tamsulosin is the most commonly used $\alpha$-blocker in MET. Within the last years, silodosin - an $\alpha$-blocker - has also been used instead of tamsulosin as MET. However, there are few studies comparing these substances for MET, and none comparing their role as MET after SWL.

\section{Aim}

The aim of this study was to retrospectively evaluate the expulsion rate of the ureteric stone fragments after SWL in patients with a single distal ureteric stone, which underwent SWL and one of the following adjuvant therapies: (A) tamsulosin $0.4 \mathrm{mg}$ once daily, (B) silodosin $8 \mathrm{mg}$ once daily, or (C) silodosin $4 \mathrm{mg}$ once daily, for a treatment period of up to 4 weeks. All patients received the NSAID lornoxicam as an additional analgesic. Beside the major aspect evaluated, i.e. success rate up to 4 weeks of treatment, we also investigated the following: pain intensity (using the visual analogue scale), adverse events induced by the medication, safety of drug administration and the reasons for possible early treatment discontinuation.

\section{Material and methods}

This retrospective study was performed in a university, tertiary stone center and evaluated the records of 190 adult patients with single distal radio opaque ureteric stones (on Kidney Ureter Bladder $X$ ray study (KUB)) treated by ESWL (single SWL session, 4000 shock waves applied at a rate of $1 / \mathrm{s}$ ) by the same experienced urologist. The indication for SWL was represented by recurrent renal colic non-responsive to medical treatment with NSAID. Only the record files of the patients who met the inclusion criteria (normal renal function - as determined by serum creatinine levels - and single distal ureteric stone, measuring 5 to $10 \mathrm{~mm}$ diameter in maximum size) were evaluated. We excluded from the evaluation patients with concomitant or previous $\beta$-blocker (antagonist of $\beta$-adrenergic receptors) treatment, pre-existing treatment with an $\alpha$-blocker for a prostatic disease, allergy/intolerance to $\alpha$-blockers or NSAID, single kidney (surgical, congenital, or functional), JJ stent inserted prior to SWL, bilateral ureteric stones or confirmed infection of the urinary tract.

This retrospective study obtained the review board approval, and met all the local and national ethical requirements applying to the study type, being conducted in accordance with the ethical standards laid down in the Declaration of Helsinki. As the $\alpha$-blocker treatment is an off-the label treatment for MET, informed consent for all the patients was obtained.

For statistical analysis, we defined three study groups, according to the medical expulsive treatment administered after the SWL sessions, as follows: group A - patients who received tamsulosin $0.4 \mathrm{mg} /$ daily, group B - patients who received silodosin $8 \mathrm{mg} /$ daily, and group $\mathrm{C}$ - patients treated with silodosin $4 \mathrm{mg} /$ daily. The local protocol involved the treatment of all the patients (additional analgesic treatment) with lornoxicam $8 \mathrm{mg}$ twice a day during the first week and then once a day until stone fragments' elimination or up to 28 days. Each patient received information concerning the daily water intake and had to fill out a questionnaire regarding: pain intensity on the visual analogue scale and adverse events. As there is no consensus regarding the scheme for MET, the choice of $\alpha$-blocker type and dose was made randomly by the urologist at the time of SWL. The patients were followed up weekly (weeks 1-3 for adverse events and pain evaluation, the $4^{\text {th }}$ evaluation for evaluation of the stone-free status).

Therapeutic success was defined as complete lack of fragments detected on unenhanced $\mathrm{CT}$ at 4 weeks after the procedure - as it appeared on patients' record files.

The stone-free rate after 4 weeks in each group was used to compare the effectiveness of the three medical treatments (either of them was adjuvant for stone expulsion after the initial SWL). Paired comparisons were made of the stone-free rates between the groups, e.g. A-B, A-C, and B-C. For each comparison the $\chi^{2}$ test was applied and 0.05 was considered the statistical significance threshold.

To evaluate the effects of repeated measures and size, a generalized estimating equations (GEE) approach was applied by means of a logistic regression 
for a repeated measures model. The GEE-based multivariate response profile approach is an analogue to repeated measures analysis of variance (repeated measures ANOVA and MANOVA) and multivariate analysis of covariance (MANCOVA). These more conventional longitudinal approaches require Gaussian response variables. In contrast, the GEE approach is well suited for skewed binary response variables (e.g. via a logarithmic link). In this model repeated measures of the response variable (success or failure of stone expulsion) in each subject were managed as clusters, while stone size was included as a factor.

\section{Results}

Patient age varied between 21 and 65, while the men/women ratio was 1.8 for the entire study. The groups were similar regarding the number of patients, sex distribution, age, stone size and degree of distension induced by the obstruction $(p>0.05$ for each aspect; $\chi^{2}$ test) (Table I).

The stone-free rates for the three groups are presented in Table II.
One can see that silodosin $8 \mathrm{mg}$ ensured a similar success rate in comparison with tamsulosin $0.4 \mathrm{mg}(p=0.9083)$, while silodosin $4 \mathrm{mg}$ is significantly less effective than tamsulosin and silodosin $8 \mathrm{mg}$.

The results of the logistic regression model, transformed into odds ratios, are presented in Table III.

One can see that the stone-free rate odds ratio was better for group B (silodosin $8 \mathrm{mg}$ ) when compared to group C (silodosin $4 \mathrm{mg}$ ) and slightly better than group A (having the same comparator - group C).

In all the logistic regression comparisons the effect of the stone size on the stone-free odds ratio is in favor of the smaller sizes.

Regarding the renal colic episodes in the three groups, we found that patients in groups $A$ and $B$ reported less pain and required only sporadic administration of additional doses of pain killers (tramadol chlorhydrate) (Tables IV and V). One can see that in group $C$, the VAS was significantly higher than in groups $A$ and $B$ for all the follow-up visits.

In groups $A$ and $B$, the visual analogue scale (VAS) for pain due to renal colic was seldom evaluated at

Table I. Distribution of the initial stone size by groups

\begin{tabular}{|c|c|c|c|c|c|c|c|c|}
\hline \multirow[t]{2}{*}{ Group } & \multicolumn{6}{|c|}{ Stone size } & \multirow[t]{2}{*}{ Total } & \multirow[t]{2}{*}{$\%$} \\
\hline & $5 \mathrm{~mm}$ & $6 \mathrm{~mm}$ & $7 \mathrm{~mm}$ & $8 \mathrm{~mm}$ & $9 \mathrm{~mm}$ & $10 \mathrm{~mm}$ & & \\
\hline A (tamsulosin 0.4 mg/day) & 17 & 19 & 8 & 8 & 4 & 5 & 61 & 32.1 \\
\hline B (silodosin 8 mg/day) & 20 & 19 & 9 & 7 & 5 & 6 & 66 & 34.7 \\
\hline C (silodosin 4 mg/day) & 21 & 16 & 9 & 7 & 5 & 5 & 63 & 33.2 \\
\hline Total & 58 & 54 & 26 & 22 & 14 & 16 & 190 & 100.0 \\
\hline
\end{tabular}

Table II. Stone-free rates within three groups, by stone size and comparisons between groups

\begin{tabular}{|c|c|c|c|c|c|c|c|c|c|}
\hline \multirow[t]{2}{*}{ Group } & \multicolumn{6}{|c|}{ Stone size } & \multirow{2}{*}{$\begin{array}{l}\text { Total \% } \\
\text { success }\end{array}$} & \multirow[t]{2}{*}{ A vs. } & \multirow[t]{2}{*}{ B vs. } \\
\hline & $5 \mathrm{~mm}$ & $6 \mathrm{~mm}$ & $7 \mathrm{~mm}$ & $8 \mathrm{~mm}$ & $9 \mathrm{~mm}$ & $10 \mathrm{~mm}$ & & & \\
\hline A & 100.0 & 100.0 & 100.0 & 87.5 & 75.0 & 60.0 & 93.4 & - & 0.9083 \\
\hline B & 100.0 & 100.0 & 100.0 & 85.7 & 80.0 & 66.7 & 93.9 & 0.9083 & - \\
\hline C & 100.0 & 93.8 & 66.7 & 57.1 & 60.0 & 40.0 & 81.0 & 0.0381 & 0.0253 \\
\hline
\end{tabular}

Table III. Statistical analysis of the logistic regression model for the study groups

\begin{tabular}{|lcccc|}
\hline Test variables & \multicolumn{4}{c|}{ Logistic regression model } \\
\cline { 2 - 5 } & A (tamsulosin $0.4 \mathrm{mg} /$ day) vs. C (silodosin $4 \mathrm{mg} /$ day) & B (silodosin $8 \mathrm{mg} /$ day) vs. C (silodosin $4 \mathrm{mg} /$ day) \\
\cline { 2 - 5 } & OR $(95 \% \mathrm{Cl})$ & $P$-value & OR $(95 \% \mathrm{Cl})$ & $P$-value \\
\hline Stone-free status & $2.3(1.73-4.56)$ & 0.0004 & $2.41(1.78-4.92)$ & $<0.0001$ \\
\hline
\end{tabular}


Table IV. Required additional pain treatment in study groups

\begin{tabular}{|c|c|c|c|c|}
\hline Group & \multicolumn{4}{|c|}{ Patients who required and received additional doses of pain killers (tramadol chlorhydrate) after SWL } \\
\hline \multirow[t]{2}{*}{ A } & \multicolumn{4}{|c|}{2 patients } \\
\hline & \multicolumn{2}{|c|}{1 patient $-100 \mathrm{mg} / 1$ day } & \multicolumn{2}{|c|}{1 patient $-2 \times 100 \mathrm{mg} / 1$ day } \\
\hline \multirow[t]{2}{*}{ B } & \multicolumn{4}{|c|}{4 patients } \\
\hline & $\begin{array}{c}1 \text { patient } \\
100 \mathrm{mg} / 1 \text { day }\end{array}$ & $\begin{array}{r}1 \\
2 \times 5\end{array}$ & day & $\begin{array}{c}2 \text { patients } \\
2 \text { days, } 50 \mathrm{mg} / \text { day }\end{array}$ \\
\hline \multirow[t]{2}{*}{ C } & \multicolumn{4}{|c|}{9 patients } \\
\hline & $\begin{array}{c}3 \text { patients } \\
1 \text { day, } 100 \mathrm{mg} / \text { day }\end{array}$ & $\begin{array}{c}2 \text { patients } \\
2 \text { days, } 100 \mathrm{mg} / \text { day }\end{array}$ & $\begin{array}{c}2 \text { patients } \\
2 \text { days, } 50 \mathrm{mg} / \text { day }\end{array}$ & $\begin{array}{c}2 \text { patients } \\
1 \text { day, } 50 \mathrm{mg} / \text { day }\end{array}$ \\
\hline
\end{tabular}

Table V. Mean visual analogue scale (VAS) values by study groups at 1, 2, 3 and 4 weeks follow-up

\begin{tabular}{|lcccc|}
\hline Variable & $\begin{array}{c}\text { Mean VAS } \\
\text { Week 1 }\end{array}$ & $\begin{array}{c}\text { Mean VAS } \\
\text { Week 2 }\end{array}$ & $\begin{array}{c}\text { Mean VAS } \\
\text { Week 3 }\end{array}$ & $\begin{array}{c}\text { Mean VAS } \\
\text { Week 4 }\end{array}$ \\
\hline $\begin{array}{l}\text { Group A } \\
\text { (tamsulosin 0.4 mg) }\end{array}$ & 6.2 & 4.1 & 4.2 & 3.2 \\
\hline $\begin{array}{l}\text { Group B } \\
\text { (silodosin 8 mg) }\end{array}$ & 5.9 & 4.3 & 4.1 & 3.1 \\
\hline $\begin{array}{l}\text { Group C } \\
\text { silodosin 4 mg) }\end{array}$ & 7.5 & 5.1 & 4.8 & 4.1 \\
\hline A vs. B ( $p$-value) & 0.031 & 0.25 & 0.32 & 0.27 \\
\hline A vs. C (p-value) & 0.038 & 0.026 & 0.047 & 0.039 \\
\hline B vs. C (p-value) & 0.026 & 0.032 & 0.041 & 0.037 \\
\hline
\end{tabular}

8 points (4 patients in each group) or 9 points (1 patient in group A).

One patient from each of groups $A$ and $B$ came back to the emergency room suffering from pain, but both had symptoms relieved by pain killers. VAS of 8 was reported in 6 patients and VAS of 9 was reported in 3 patients.

From the 22 cases of failure reported after 4 weeks of treatment, in 19 cases another ESWL procedure was performed, in 1 case semirigid ureteroscopy was done at the patient's choice, and in two symptomatic cases (from group C), without significant ureterohydronephrosis, the expulsion therapy with silodosin $8 \mathrm{mg}$ was continued at the patient's preference, stone-free status being reached in both cases after an additional 2 and 3 weeks respectively.

\section{Discussion}

To our knowledge this retrospective study appears to be the first aiming to compare the effects of tamsulosin $0.4 \mathrm{mg}$ with silodosin $4 \mathrm{mg}$ and $8 \mathrm{mg}$ as medical expulsive treatment after SWL. A recent meta-analysis showed that all the previous published studies compared tamsulosin $0.4 \mathrm{mg}$ with silodosin $8 \mathrm{mg}$, revealing higher expulsion rates for silodosin $8 \mathrm{mg}$, none of them evaluating the effect of lower dose silodosin [11]. Although controversies exist, $\alpha$-blocker therapy is recommended by the European Association of Urology Guidelines as medical expulsive treatment, especially for distal ureteric stones, facilitating the stone passage due to the relaxation of the smooth muscle of the ureter [12].

$\alpha 1 \mathrm{~A}-, \alpha 1 \mathrm{~B}-$ and $\alpha 1 \mathrm{D}-\mathrm{ARs}$ are the three types of $\alpha 1$ adrenoceptors, the most frequent being the $\alpha 1 \mathrm{D}$ subtype, followed by $\alpha 1 \mathrm{~A}$ and $\alpha 1 \mathrm{~B}$ [13].

Tamsulosin is a uroselective $\alpha$-blocker owing to its selectivity as an antagonist of $\alpha 1 \mathrm{~A}$ receptors. Tamsulosin $0.4 \mathrm{mg}$ once daily was reported to increase the rate of ureteric stone expulsion [7, 14-18]. The existing literature is abundant in studies that recommend $\alpha$-blockers in the scheme of expulsion treatment, motivated by the fact that the ureter contracted by stimulation of $\alpha 1$-adrenergic receptors may im- 
pede elimination of the stone and stone fragments, while the use of $\alpha$-blockers may allow an increase of urine flow by ureteric muscle relaxation, with the respective washout effect, but also by an increase of intra-ureteric pressure gradient around the stone, which may help stone expulsion [19]. There are data suggesting that similar results can be obtained with doxazosin or terazosin, by a class effect [12].

The affinity of silodosin for $\alpha 1$ A receptors is 150 times higher than for $\alpha 1 \mathrm{D}$ in comparison with tamsulosin, which is 100-fold higher; thus, we could, at least theoretically, expect better results [20]. As silodosin $4 \mathrm{mg}$ can be successfully used for treatment of lower urinary tract symptoms, we decided to use it in order to evaluate its efficacy as MET.

Adrenergic receptors $\alpha 1 \mathrm{~A}$ and $1 \mathrm{D}$ are more frequent in the ureter than $1 \mathrm{~B}$, and $\alpha 1 \mathrm{D}$ has the highest density in the distal ureter [21]. However, the literature regarding the impact of specific $1 \mathrm{~A}$ vs. $1 \mathrm{D}$ antagonist is not very conclusive. Comparison between naftopidil (selective $\alpha 1 D$ antagonist) and silodosin $8 \mathrm{mg}$, having an affinity for $\alpha 1 \mathrm{~A}$, which is 56 times higher than for $\alpha 1 \mathrm{D}$, revealed that inhibition of $\alpha 1 \mathrm{~A}$ receptors is more important for expulsion facilitation than that of $\alpha 1 D[22,23]$. Alpha 1D receptors are better represented than $1 \mathrm{~A}$ in each ureteric region, so they could play the key role in stone expulsion [24].

Our results reveal similar expulsion rates for tamsulosin $0.4 \mathrm{mg}$ and silodosin $8 \mathrm{mg}$. Meanwhile, it seems that silodosin $4 \mathrm{mg}$ has inferior results in terms of stone-free rate, the stone-free odds ratio being 2.3 and 2.41 for tamsulosin $0.4 \mathrm{mg}$ and silodosin $8 \mathrm{mg}$ compared to silodosin $4 \mathrm{mg}$, respectively. Moreover, the pain score (VAS) was significantly higher in patients treated with silodosin $4 \mathrm{mg}$ compared with the other two groups.

The strong points of this study are the homogeneity of the groups, the inclusion criteria, the single person performing the ESWL procedure (thus, biases related to the technique being avoided) and the simple follow-up schedule. Also, we acknowledge the relatively small size of the groups, the retrospective nature of the study and the lack of stone characterization by density (as only KUB was performed before the procedure), further larger studies being necessary.

\section{Conclusions}

$\alpha$-Blocker treatment after ESWL with silodosin $8 \mathrm{mg}$ offers a similar stone-free rate compared with tamsulosin $0.4 \mathrm{mg}$, being well tolerated. A lower dose of silodosin (4 mg) has significantly poor results, irrespective of ureteric stone size, with more frequent renal colic and severe pain.

\section{Conflict of interest}

The authors declare no conflict of interest.

\section{References}

1. Falahatkar S, Khosropanah I, Doustkhah Vajary A, et al. Is there a role for tamsulosin in extra corporeal shockwave lithotripsy for renal and ureteric calculi? J Endourol 2011; 25: 495-8.

2. Bhagat SK, Chacko NK, Kekre NS, et al. Is there a role for tamsulosin in shock wave lithotripsy for renal and ureteral calculi? J Urol 2007; 177: 2185-8.

3. Choi NY, Ahn SH, Han JH, Jang IH. The effect of tamsulosin and nifedipine on expulsion of ureteral stones after extracorporeal shock wave lithotripsy. Kor J Urol 2008; 49: 150-4.

4. Kim JH, Roh BS, Lee YH, et al. Effect of tamsulosin $0.2 \mathrm{mg}$ on the short-term treatment of urinary stones: multicenter, prospective, randomized study. Kor J Urol 2009; 50: 586-90.

5. Hussein M. Does tamsulosin increase stone clearance after shockwave lithotripsy of renal stones? A prospective, randomized, controlled study. Scand J Urol Nephrol 2010; 44: 27-31.

6. John TT, Razdan S. Adjunctive tamsulosin improves stone free rate after ureteroscopic lithotripsy of large renal and ureteric calculi: a prospective randomized study. Urology 2010; 75: 1040-2

7. Kim JW, Cho DY, Lee JG. Effect of tamsulosin on the expected treatment of upper and lower ureteral stones. Kor J Urol 2007; 48: 724-30.

8. Aldemir M, Uçgül YE, Kayıgil O. Evaluation of the efficiency of tamsulosin and rowatinex in patients with distal ureteral stones: a prospective, randomized, controlled study. Int Urol Nephrol 2011; 43: 79-83.

9. Zhang MY, Ding ST, Lu JJ, et al. Comparison of tamsulosin with extracorporeal shock wave lithotripsy in treating distal ureteral stones. Chin Med J 2009; 122: 798-801.

10. Erkan E, Toktas GM, Kocaaslan R, et al. Efficacy of tamsulosin and deflazocort in management of distal ureteral stones: a prospective randomized trial. Eur Urol Suppl 2010; 9: 581.

11. Hsu YP, Hsu CW, Bai CH, et al. Silodosin versus tamsulosin for medical expulsive treatment of ureteral stones: a systematic review and meta-analysis. PLoS One 2018; 13: e0203035

12. Türk C, Petrik A, Sarica K, et al. EAU Guidelines on diagnosis and conservative management of urolithiasis. Eur Urol 2016; 69: 468-74.

13. Sasaki S, Tomiyama Y, Kobayashi S, et al. Characterization of alpha1-adrenoceptor subtypes mediating contraction in human isolated ureters. Urology 2011; 77: 762e713-67.

14. Parsons JK, Hergan LA, Sakamoto K, et al. Efficacy of alphablockers for the treatment of ureteral stones. J Urol 2007; 177: 983-7.

15. Dellabella M, Milanese G, Muzzonigro G. Randomized trial of the efficacy of tamsulosin, nifedipine and phloroglucinol 
in medical expulsive therapy for distal ureteral calculi. J Urol 2005; 174: 167-72.

16. Kobayashi M, Naya Y, Kino M, et al. Low dose tamsulosin for stone expulsion after extracorporeal shock wave lithotripsy: efficacy in Japanese male patients with ureteral stone. Int J Urol 2008; 15: 495-8.

17. Naja V, Agarwal MM, Mandal AK, et al. Tamsulosin facilitates earlier clearance of stone fragments and reduces pain after shockwave lithotripsy for renal calculi: results from an openlabel randomized study. J Urol 2008; 72: 1006-11.

18. Salem T. Medical treatment for small stones in the lower ureter. UroToday Home 2009; 2. doi: 10.3834/uij.1944-5784.2009.10.05.

19. Ahmed AF, Al-Sayed AY, Ahmed AF, Al-Sayed AY. Tamsulosin versus alfuzosin in the treatment of patients with distal ureteral stones: prospective, randomized, comparative study. Korean J Urol 2010; 51: 193-7.

20. Özsoy M, Liatsikos E, Scheffbuch N, Kallidonis P. Comparison of silodosin to tamsulosin for medical expulsive treatment of ureteral stones: a systematic review and meta-analysis. Urolithiasis 2016; 44: 491-7.

21. Sigala S, Dellabella M, Milanese G, et al. Evidence for the presence of alpha1 adrenoceptor subtypes in the human ureter Neurourol Urodyn 2005; 24: 142-8.

22. Shibata K, Foglar R, Horie K, et al. KMD-3213, a novel, potent, alpha 1a-adrenoceptor-selective antagonist: characterization using recombinant human alpha 1-adrenoceptors and native tissues. Mol Pharmacol 1995; 48: 250-8.

23. Tsuzaka Y, Kaneko T, Matsushima H, et al. Efficacy of low dose tamsulosin in medical expulsive therapy for ureteral stones in Japanese male patients: a randomized controlled study. Int J Urol 2011; 17: 462-5.

24. Itoh MO, Cicek T, Ozturk B, et al. What shall we do for treatment of stone street occurred after ESWL? J Endourol 2007; 21: 90.

Received: 3.11.2019, accepted: 12.12.2019. 